\title{
Determinan Entrepreneurial Motivation Mahasiswa Perbankan Syariah
}

\author{
Siswanto \\ Islamic Banking Department, Faculty of Economy \\ Maulana Malaik Ibrahim, State Islamic University of Malang, \\ Indonesia
}

\begin{abstract}
This study was conducted to explon factors motivating students to be entreprenteur. Factor analysis approach used to attain the objective. The analysis used four stages, namely, dnoose a zariable, variable extraction, rotation and indentified variables. Totul sample of the reseanch were 100 respondents. The results showed some biograplical characteristics which induded chanacteristics based on age, gender, entrepreneurial intentions, type of business, opinions, and backgrounds. Based on the results, there were six importunt factors which motionted students to be entrepreneur, nanely, need for achicuement, locus of control, extemial environment, selfefficacy, material encouragement, and independence.
\end{abstract}

Keywoords: Enifrepneneunial motivation, Islamic boinking student, Factor analysis

\section{PENDAHULUAN}

Penelitian terdahulu tentang entrepreneurial motioation (motivasi wirausaha) seringkali dihubungkan dengan faktor sifat kepribadian, antara lain; pertama, independence (Shane, et al., 2003; Sarri and Trihopoulou, 2005), kedua, need for achicoement (Shane, at al., 2003; Pillis \& Reardon, 2007; Longenecker, et al., 2000: 10; Ahmad, 2010; Pandey, 2011), ketiga, risk taking (Longenecker, et al., 2000: 10; Stewart, Cerland, and Carland, 2004) dan lain-lain. Beberapa peneliti percaya bahwa ciri-ciri kepribadian bawaan (personality traits) adalah motivator utama, sementara yang lain percaya faktor eksternal/situasional (push-pull) lebih penting. Ciri-ciri kepribadian, seperti kebutuhan untuk berprestasi (need for achievement), toleransi untuk ambiguitas (tolenance for ambiguity), keinginan untuk berinovasi (desire for innovatize), kecenderungan untuk mengambil risiko (propensity for risk-taking) dan preferensi untuk locus of control, 
semuanya telah ditunjukkan mempengaruhi aktivitas entreprenesirial (Benzing and $\mathrm{Chu}, 2009$ ).

Teori yang sering diaplikasikan dalam penelitian tentang motivasi wirausaha adalah teori dari McClelland, yakni teori kebutuhan untuk berprestasi (need for achievement) dan teori locus of control dari Rotter (Littunen, 2000). Menurut Teori McClelland, seseorang yang memiliki keinginan yang kuat untuk meraih apa yang diharapkan akan berusaha keras menyelesaikan permasalahan yang dihadapi, merancang target, dan berupaya menggapai target yang dirancang dengan upaya mereka sendiri. Lebih lanjut, teori tersebut menjelaskan bahwa orang memiliki kebutuhan untuk berprestasi tinggi akan menjadi seorang wirausahawan sukses. Sedangkan teori locus of control dari Rotter menunjukkan bahwa pusat kendali seorang individu terbagi atas kendali internal (intemal locus of kendali) dan kendali eksternal (external locus of control). Pusat kendali internal menunjukkan pada kendali atas kehidupan seorang individu, dimana hasil dari tindakan yang dilakukan tergantung pada perilaku dan karakteristik yang dimilikinya. Sedangkan pusat kendali eksternal sejenis kendali yang berfokus pada tindakan pihak lain, nasib/takdir, keberuntungan atau peluang yang ada.

Berdasarkan hasil penelusuran penelitian tentang motivasi wirausaha tersebut menunjukkan bahwa motivasi wirausaha telah memperoleh perhatian yang banyak dari para peneliti. Walaupun terdapat penelitian yang cukup banyak dan mendalam tentang motivasi wirausaha, namun masih diperlukan kajian kritis untuk melengkapi keterbatasan penelitian terdahulu (Kowi \& Kole, 1991; Carsrud \& Brannback, 2011), terutama berkaitan dengan eksplorasi motivasi wirausaha berdasarkan nilai-nilai agama (Valliere, 2007; Kauanui et al., 2010). Pentingnya eksplorasi motivasi wirausaha berdasar nilai-nilai agama, khususnya pada komunitas muslim ini juga dinyatakan oleh Yazilmiwati dan Ithamie (2011). Mereka menyatakan bahwa selama ini tema wirausaha fokus pengamatannya pada komunitas non muslim. Padahal, Islam mendorong umatnya untuk menjadi wirausahawan sebagaimana dicontahkan Nabi Muhammad SAW. Berdasarkan celah penelitian (gap research) ini, peneliti berupaya mengeksplorasi motivasi wirausaha pada komunitas Muslim.

Komunitas Muslim yang menjadi obyek penelitian ini adalah para mahasiswa Muslim pada Jurusan Perbankan Syariah di Fakultas Ekonomi UIN Maulana Malik Ibrahim Malang. Beberapa argumentasi yang menjadi pertimbangan pemilihan obyek penelitian, 
antara lain; 1) Jurusan ini memilikł kepedulian yang tinggi dalam menumbuhkembangkan semangat kewirausahaan ditunjukkan dengan adanya konsentrasi entrepreneurship and banking, 2) Terdapat beberapa komunitas mahasiswa Muslim yang tergabung dan mengembangkan bisnis, seperti Pecinta Bisnis Syariah (PBS) dan komunitas Event Organizer, 3) Para mahasiswa penggiat wirausaha ini telah memiliki produk dan cukup berkembang, dan 4) Adanya beberapa capaian prestasi dari para mahasiswa yang memiliki semangat kewirausahaan ying tinggi, seperti berhasil menyelenggarakan even berskala lokal dan nasional, bahkan internasional berupa keberhasilan mendatangkan kuliah tamu dengan pemateri ilmuwan ekonomi Islam dari Ummul Qurra University, Prof. Dr. Khalaf Solaiman.

Untuk menggali dan menentukan determinan atau faktorfaktor yang mendorong (motivasi) wirausaha dari para komunitas muslim ini digunakan alat analisis faktor (factor analysis). Hair et al., (1998: 95) menyatakan bahwa tujuan umum dari teknik analisis faktor adalah untuk menentukan sejumlah faktor dari serangkaian variabel awal, yang jumlahnya cukup banyak, menjadi sejumlah kecil dengan cara meminimalkan informasi yang hilang. Variabel dalam konteks ini adalah motivasi wirausaha pada komunitas wirausaha Muslim muda, yakni mahasiswa Muslim pada jurusan Perbankan syariah UIN Maliki Malang.

Berdasarkan latar belakang yang dibangun dari celah penelitian (research gap brsed-on academic research), alasan memilih obyek pada komunitas wirausaha Muslim, dan teknik analisis yang digunakan dalam penelitian ini, maka dikemukana tujuan penelitian adalah menggali faktor-faktor atau determinan yang memotivasi para mahasiswa Muslim untuk berwirausaha. Tujuan ini dapat dicapai dengan teknik analisis faktor (factor analysis technique) karena teknik ini berguna dalam mengidentifikasi struktur dan faktor dengan cara meringkas data dan mengurangi data atau mereduksi sejumlah variabel.

\section{TINJAUAN PUSTAKA}

Motivasi

Motivasi merupakan salah satu dari unit analisis dalam kerangka teori kognitif. Kesadaran/pengertian (cognition), tindakan untuk mengetahui bagian informasi, merupakan elemen mendasar 


\section{Determinan Enterpreneurial Motivation}

dari kerangka teori kognitif (Luthans, 2002:25). Menurut Luthan (2002: 250-258) motivasi dapat dibedakan berdasarkan pendekatan proses psikologis dasar (a basic psychological process) dan pendekatan motivasi kerja (uork-motioution approach). Banyak para ahli perilaku yang sependapat bahwa motivasi merupakan bagian penting pendekatakan mikro dari perilaku organisasi. Walaupun demikian, faktor lain seperti persepi, sikap, pembelajaran dan kepribadian, serta lingkungan dipertimbangkan dalam menjelaskan perilaku. Luthans (2002: 259) menyatakan bahwa berdasarkan pendekatan basic psychological process dapat diklasifikasikan lagi menjadi motif primer/utama (primary motive), motif umum (general motive), dan motif sekunder (secondary motive).

Motif primer meliputi kebutuhan dasar yang dimiliki oleh manusia, antara lain; rasa lapar, haus, tidur, menghindari dari rasa sakit, hubungan seksual, dan berkeluarga. Sedangkan general motive meliputi sejumlah motif yang berada di wilayah yang kurang jelas antara motif primer dan motif sekunder. General motrive ini disebut pula dengan stimulus motive, berupa antara lain; rasa ingin tahu, penyalahgunaan, dan kasih sayang. Adapun secondary motives meliputi antara lain; kebutuhan untuk berprestasi (need for achievement), kebutuhan memperoleh kekuasaan (need for poiver), kebutuhan untuk berafiliasi, kebutuhan mendapatkan rasa aman (need for security), dan kebutuhan memperoleh status, serta kebutuhan intrinsik-ekstrinsik (intrinsic-extrinsic motives).

McShane dan Glinow (2003: 132) cenderung membedakan teori motivasi kerja (work motivation) karyawan menjadi dua kategari utama, yakni; 1) content theories of motivation, 2) process theories of motivation. Content theories of motioation menjelaskan tentang dinamika dari kebutuhan karyawan, seperti mengapa seseorang memiliki kebutuhan berbeda pada waktu yang berbeda. Melalui pemahaman kebutuhan karyawan, kita dapat menciptakan kondisi yang dapat memotivasi karyawan. Sedangkan process theories of motization menjelaskan tentang proses bagaimana kebutuhan dirubah kedalam bentuk perilaku tertentu. Teori proses ini menjelaskan kepada kita tentang mengapa seseorang melalukan perilaku tertentu dalam organisasi. Sedangkan, Segal, Borgia, Schoenfeld (2005) menjelaskan content theories berkaitan dengan hal/ciri spesifik dari seorang individi that memprakarsai, menopang, dan menahan perilaku. Process theories berhubungan dengan bagaiman perilaku tersebut dimulai, ditopang, dan dihentikan. 


\section{Determinan Enterpreneurial Motivation}

dari kerangka teori kognitif (Luthans, 2002:25). Menurut Luthan (2002: 250-258) motivasi dapat dibedakan berdasarkan pendekatan proses psikologis dasar (a basic psychological process) dan pendekatan motivasi kerja (uork-motioution approach). Banyak para ahli perilaku yang sependapat bahwa motivasi merupakan bagian penting pendekatakan mikro dari perilaku organisasi. Walaupun demikian, faktor lain seperti persepi, sikap, pembelajaran dan kepribadian, serta lingkungan dipertimbangkan dalam menjelaskan perilaku. Luthans (2002: 259) menyatakan bahwa berdasarkan pendekatan basic psychological process dapat diklasifikasikan lagi menjadi motif primer/utama (primary motive), motif umum (general motive), dan motif sekunder (secondary motive).

Motif primer meliputi kebutuhan dasar yang dimiliki oleh manusia, antara lain; rasa lapar, haus, tidur, menghindari dari rasa sakit, hubungan seksual, dan berkeluarga. Sedangkan general motive meliputi sejumlah motif yang berada di wilayah yang kurang jelas antara motif primer dan motif sekunder. General motrive ini disebut pula dengan stimulus motive, berupa antara lain; rasa ingin tahu, penyalahgunaan, dan kasih sayang. Adapun secondary motives meliputi antara lain; kebutuhan untuk berprestasi (need for achievement), kebutuhan memperoleh kekuasaan (need for poiver), kebutuhan untuk berafiliasi, kebutuhan mendapatkan rasa aman (need for security), dan kebutuhan memperoleh status, serta kebutuhan intrinsik-ekstrinsik (intrinsic-extrinsic motives).

McShane dan Glinow (2003: 132) cenderung membedakan teori motivasi kerja (work motivation) karyawan menjadi dua kategari utama, yakni; 1) content theories of motivation, 2) process theories of motivation. Content theories of motioation menjelaskan tentang dinamika dari kebutuhan karyawan, seperti mengapa seseorang memiliki kebutuhan berbeda pada waktu yang berbeda. Melalui pemahaman kebutuhan karyawan, kita dapat menciptakan kondisi yang dapat memotivasi karyawan. Sedangkan process theories of motization menjelaskan tentang proses bagaimana kebutuhan dirubah kedalam bentuk perilaku tertentu. Teori proses ini menjelaskan kepada kita tentang mengapa seseorang melalukan perilaku tertentu dalam organisasi. Sedangkan, Segal, Borgia, Schoenfeld (2005) menjelaskan content theories berkaitan dengan hal/ciri spesifik dari seorang individi that memprakarsai, menopang, dan menahan perilaku. Process theories berhubungan dengan bagaiman perilaku tersebut dimulai, ditopang, dan dihentikan. 
Entrepreneurship (Kewirausahaan)

Entrepreneurship memiliki definisi yang beraneka ragam dan terdapat perbedaan dalam kerangka berpikir (Shane and Venkataraman, 2000). Dalam penelitian ini, definisi entrepreneurship mengacu pada pendapat Shane \& Venkataraman (2000), yang menyatakan bahwa: "Entrepreneurship as the process by which opportunities to create future goods and services are discovered, exaluated, and exploited."

Berdasarkan definisi ini memiliki implikasi bahwa entrepneneurship merupakan proses kreatif dan aktivitas kolektif. Setiap orang dapat menjadi entrepreneur manakala memiliki ide kreatif menemukan dan memodifikasi produk atau jasa yang berguna bagi organisasinya, dan seorang entripreneur bukan hanya seorang pendiri atau pemilik perusahaan (Shane, et al., 2003). Proses entrepreneurship melibatkan peran manusia. Kemampuan (ability) dan harapan (uillingnes) yang dimiliki oleh manusia akan menentukan keberhasilan proses entrepreneurship. Huarng \& Yu (2011) menyatakan bahwa entrepreneurship merupakan aktivitas kolektif, sedangkan individu merupakan bagian dari aktivitas kolektif tersebut.

Selama beberapa tahun, penelitian tentang entrepreneurship seringkali dihubungkan dengan peran faktor lingkungan eksternal (Fereidouni et al., 2010). Walaupun penelitian-penelitian tersebut memberikan pemahaman yang semakin jelas terhadap proses entrepreneurship, namun penelitian tersebut mengabaikan peran manusia. Entrepreneurship akan tergantung pada pengambilan keputusan yang dilakukan orang tentang bagaimana untuk menjalankan proses tersebut. Penelitian ini memiliki pendapat yang sama dengan pernyataan Shane et al. (2003) bahwa peran manusia ketika memutuskan melakukan proses entrepreneurial akan mempengaruhi keberhasilan proses tersebut. Walaupun ada beberapa penelitian tentang motivasi manusia pada entrepreneurial (Shane et al, 2003; Buang \& Yousef, 2006; Carsrud \& Brannback, 2011), namun peneliti berpendapat bahwa penelitian motivasi manusia pada proses entrepreneurial berdasarkan nilai-nilai agama masih belum memadai.

\section{Motivasi dan Entrepreneurship}

Shook, Priem, McGee, (2003) menyatakan bahwa motivasi memiliki peran penting dalam memprediksi keinginan menjadi entrepreneur. Entrepreneurship melibatkan peran manusia. Proses 
entrepneneurship terjadi karena orang-orang bertindak untuk mengejar peluang. Shane et al,, (2003) menyatakan bahwa motivasi manusia menentukan keputusan menjadi entrepreneur dan proses entrepreneurship. Perbedaan motivasi akan mempengaruhi proses entopreneurship.

Motivasi entrepreneurial berdasarkan kajian empiris masih belum memadas (Kowi \& Kole, 1991; Carsrud \& Brannback, 2011). Sedangkan menurut Valliere (2007) dan Kauanui et aL (2010) menyatakan eksplorasi motivasi entrepreneurial berdasarkan nilai-nilai agama masih belum tergali secara memadai. Selanjutnya, peneliti melacak beberapa penelitian sebelumnya yang telah mengeksplorasi motivasi dan pengaruhnya terhadap entrepreneurial.

Para peneliti telah mengambil berbagai pendekatan untuk menjelaskan apa yang memotivasi individu untuk memulai bisnis mereka sendiri. Beberapa peneliti percaya bahwa ciri-ciri kepribadian bawaan (personality traits) adalah motivator utama, sementara yang lain percaya faktor eksternal/situasional (mush-puil) lebih penting. Ciri-ciri keprihadian, seperti kebutuhan untuk berprestasi (need for achiccement), toleransi untuk ambiguitas (tolerance for anbiguity), keinginan untuk berinovasi (desire for imnoontice), kecenderungan untuk mengambil risiko (propensity for risk-tuking) dan preferensi untuk locis of control, semuanya telah ditunjukkan mempengaruhi aktivitas entrepremential (Benzing \& Chu, 2009).

\section{METODE PENEITIAN}

Penelitian ini menggunakan paradigma positivis, yakni berupaya untuk menjelaskan dan memprediksikan faktor-faktor yang menentukan (determinan) yang memotivasi para mahasiswa perbankan syariah untuk mengembangkan wirausaha. Strategi dan pendekatan menggunakan metode studi kasus. Pendekatan studi kasus berguna untuk mengamati serangkaian eksperimen yang ditemukan di lapangan berdasarkan wawancara dan penentuan closed instrument. Wawancara berguna dalam menggali faktor-faktor awal (origin) yang diproyeksikan sebagai faktor yang memotivasi wirausahawan yakni parn mahasiswa Jurusan Perbankan Syariah Tersebut. Dari hasil wawancara, disusun suatu closed instrument yang akan dipergunakan untuk mengukur persepsi mereka terhadap faktor-faktor yang telah dimasukan dalam instrument tersebut. Teknik analisis faktor berguna dalam mereduksi faktor menjadi minimal dengan tidak menghilangkan makna didalamnya. 
Sampel merupakan bagian populasi keseluruhan yang dapat digunakan untuk generalisasi hasil penelitian. Pemilihan sampel penelitian diseleksi berdasarkan tujuan (purpose) dan kriteria tertentu. Dengan teknik atau cara ini diharapkan mampu menyeleksi responden yang diharapkan. Kriteria yang ditetapkan diantaranya adalah telah memiliki usaha dan memiliki orientasi yang kuat mengembangkan usaha untuk saat ini dan masa yang akan datang. Jumlah sample penelitian ini sebanyak 100 responden. Analisa faktor merupakan salah satu teknik analisa yang interdepence dimana semua variabel secara simultan dipertimbangkan, semua variabel saling terkait satu dengan yang lainnya. Faktor-faktor yang dibentuk tidak digunakan untuk memprediksikan variabel tergantung. Factor analysis merupakan metode statistik multivariate yang memiliki tujuan, yakni; 1) Meringkas dan mereduksi data atau variabel, 2) mendefinasikan struktur yang terdapat pada data matrik. Proses Analisis Faktor secara garis besar meliputi; 1) memilih variabel yang layak dimasukkan dalam analisis factor, 2) setelah sejumlah variabel terpilih, maka dilakukan ekstraksi variabel tersebut hingga menjadi satu atau beberapa factor, 3) faktor yang terbentuk, pada banyak kasus, kurang menggambarkan perbedaan diantara faktor-faktor yang ada, maka diperlukan proses rotasi untuk memperjelas apakah faktor yang terbentuk sudah secara signifikan berbeda dengan faktor lain, 4) menamakan faktor yang ada.

Secara konsep tujuan utama analisa faktor adalah untuk mereduksi jumlah variabel dengan cara mirip seperti pengelompokan variabel. Di dalam analisa faktor, variabelvariabel dikelompokkan berdasarkan korelasinya. Variabel yang berkorelasi tinggi akan berada dalam kelompok tertentu membentuk suatu faktor. Dalam penelitian sosial, ekonomi, psikologi, pendidikan kebanyakan variebel yang menjadi perhatian dalam penelitian tidak dapat diamati atau diukur secara langsung, dengan demikian dikembangkan beberapa indikator untuk mengukur variabel tersebut, pengelompokkan indikator-indikator dapat berguna untuk menentukan dimensi-dimensi dari variabel tersebut. Faktor dalam hal ini merupakan hasil pengelompokan indikator. Analisa faktor menurut kegunanaannya dapat dikelompokkan menajdi 2 pembahasan yakni; analisa faktor eksploratori dan analisa faktor konfirmatori. Analisa faktor eksplotori bertujuan untuk mengetahui faktor-faktor penyusun dari dimensi kehiduupan. Sedangkan analisa faktor konfirmatori bertujuan untuk menguji kembali landasan teori dan konsep yang 
dimiliki, sehingga dalam hal ini analisa faktor konfirmatori dapat berfungsi sebagai uji validitas dan reliabilitas.

\section{HASIL PENELITIAN}

\section{Analisis Deskripsi Responden}

Jumlah responden dalam penelitian ini adalah sejumlah 100 responden yang meliputi mahasiswa Jurusan Perbankan Syariah Fakultas Ekonomi Universitas Islam Negeri Maulana Malik Ibrahim Malang. Data deskripsi responden ini meliputi karakteristik, yakni; usia, jenis kelamin, niat berwirausaha, jenis usaha, tingkat penghasilan, pekerjaan orang tua. Usia responden dalam penelitian ini mulai usia 17 tahun hingga 22 tahun. Responden terbanyak berusia 20 tahun, yakni sejumlah 49 orang atau sebesar $49 \%$. Disusul dengan responden berusia 19 tahun, berjumlah 28 orang, atau sebesar $28 \%$. Responden berusia 21 tahun sebanyak 15 orang $(15 \%)$, responden berusia 22 tahun sebanyak 5 orang (5\%), responden berusia 18 tahun sejumlah 2 orang (2), sedangkan yang paling muda berusia 17 tahun sejumlah 1 orang $(1 \%)$. Responden penelitian ini terdiri atas mahasiswa semester satu sampai dengan semester 7 .

Tabel 1. Data responden berdasarkan usia

\begin{tabular}{lcccc}
\hline Usia & Frequency & Percent & $\begin{array}{c}\text { Valid } \\
\text { Percent }\end{array}$ & Cumulative Percent \\
\cline { 2 - 5 } Usia 17 Tahun & 1 & 1.0 & 1.0 & 1.0 \\
Usia 18 Tahum & 2 & 2.0 & 2.0 & 3.0 \\
Usia 19 Tahun & 28 & 28.0 & 28.0 & 31.0 \\
Usia 20 Tahun & 49 & 49.0 & 49.0 & 80.0 \\
Usia 21 Tahun & 15 & 15.0 & 15.0 & 95.0 \\
Usia 22 Tahun & 5 & 5.0 & 5.0 & 100.0 \\
Total & 100 & 100.0 & 100.0 & \\
\hline
\end{tabular}

Sumber: data diolah

Data responden berdasarkan jenis kelamin menunjukkan bahwa responden perempuan lebih besar dibandingkan dengan responden laki-laki. 
Tabel 2. Data responden berdasarkan jenis kelamin

\begin{tabular}{lcccc}
\hline Jenis Kelamin & Frequency & Percent & Vallid Percent & Cumulative Percent \\
\cline { 2 - 5 } Laki_Laki & 39 & 39.0 & 39.0 & 39.0 \\
Perempuan & 61 & 61.0 & 61.0 & 100.0 \\
Total & 100 & 100.0 & 100.0 & \\
\hline
\end{tabular}

Sumber: data diolah

Responden laki-laki sebanyak 39 orang atau sebesar $39 \%$, sedangkan responden perempuan sebesar 61 orang, atau sebesar $61 \%$. Responden berjenis kelamin perempuan memang lebih banyak dibandingkan dengan responden laki-laki, karena peminat jurusan perbankan syariah di UIN Maliki Malang didominasi oleh kaum hawa. Hal ini ditunjukkan data dari jurusan bahwa lebih dari $50 \%$ mahasiswa perbankan syariah di FE UIN Maliki Malang adalah perempuan.

Karakteristik responden berdasarkan keinginan atau niat untuk berwirausaha menunjukkan hasil bahwa sebagian besar responden berniat untuk berwirausaha.

Tabel 3. Data responden berdasarkan niat berwirausaha

\begin{tabular}{lcccc}
\hline Niat Berwirausaha & Frequency & Percent & $\begin{array}{c}\text { Valid } \\
\text { Percent }\end{array}$ & Cumulative Percent \\
\cline { 2 - 5 } Memiliki Niat & 98 & 98.0 & 98.0 & 98.0 \\
Tidak Memiliki Niat & 2 & 20 & 2.0 & 100.0 \\
Total & 100 & 100.0 & 100.0 & \\
\hline
\end{tabular}

Sumber; data diolah

Berdasarkan hasil analisis deskriptif menunjukkan bahwa dari total 100 responden $98 \%$ responden, atau sebanyak 98 orang memiliki niat untuk berwirausaha. Sedangkan sisanya, yakni 2 orang $(2 \%)$ saja yang tidak memiliki keinginan untuk berwirausaha. Hal ini menunjukkan konsistensi temuan berdasarkan hasil observasi beberapa periode tentang minat wirausaha.

Karakteristik responden berdasarkan rintisan usaha menjelaskan tentang jumlah responden yang telah memulai atau merintis usahanya. 
Determinan Enterpreneurial Motivotion

Tabel 4. Data responden berdasarkan rintisan usaha

\begin{tabular}{lcccc}
\hline \multicolumn{1}{c}{ Rintisan usaha } & Frequency & Percent & $\begin{array}{c}\text { Valid } \\
\text { Percent }\end{array}$ & $\begin{array}{c}\text { Cumulative } \\
\text { Percent }\end{array}$ \\
\cline { 2 - 5 } & 31 & 31.0 & 31.0 & 31.0 \\
$\begin{array}{l}\text { Sudah Memiliki Rintisan } \\
\text { Usaha }\end{array}$ & 69 & 69.0 & 69.0 & 100.0 \\
$\begin{array}{l}\text { Belum Memiliki Rintisan } \\
\text { Usaha }\end{array}$ & 100 & 100.0 & 100.0 & \\
Total & & &
\end{tabular}

Sumber: data diolah

Berdasarkan hasil analisis diskriptif menunjukkan bahwa $31 \%$ ( 31 orang) responden yang telah memulai dan merintis usahanya. Sedangkan, sejumlah $69 \%$ responden yang belum memulai usahanya. Hal ini disebabkan karena belum ada keberanian untuk memulai usaha, adanya keterbatasan modal, dan masih belum terasahnya pengalaman.

Karakteristik responden berdasarkan jenis usaha menjelaskan lebih detil tentang informasi sebelumny, yakni $31 \%$ orang yang telah memiliki usaha tersebut bergerak dalam bidang apa saja.

Tabe1 5. Data responden berdasarkan jenis usaha.

\begin{tabular}{lcccc}
\hline \multirow{1}{*}{ Jenis Usha } & Frequency & Percent & Valid Percent & Cumulative Percent \\
\cline { 2 - 5 } Jasa & 15 & 15.0 & 26.3 & 26.3 \\
Perdagangan & 41 & 41.0 & 71.9 & 98.2 \\
Lainnya & 1 & 1.0 & 1.8 & 100.0 \\
Total & 57 & 57.0 & 100.0 & \\
Missing System & 43 & 43.0 & & \\
\multicolumn{1}{r}{ Total } & 100 & 1000 & & \\
\hline
\end{tabular}

Sumber: data diolah

Hasil analisis deskriptif menunjukkan bahwa sebagian besar responden yang memiliki usaha bergerak dalam bidang perdagangan atau jual beli barang, yakni sebesar $41 \%$. Sedangkan sisanya mereka bergerak dalam bidang jasa dan bidang lainnya.

Karakteristik responden berdasarkan penghasilan usaha menjelaskan tentang jumlah penghasilan responden.

Tabel 6. Data responden berdasarkan penghasilan usaha.

\begin{tabular}{lcccc}
\hline \multicolumn{1}{c}{ Penghasilan Usaha } & Frequency & Percent & $\begin{array}{c}\text { Valid } \\
\text { Percent }\end{array}$ & $\begin{array}{c}\text { Cumulative } \\
\text { Percent }\end{array}$ \\
\cline { 2 - 5 } Kurang dari Satu Juta & 44 & 44.0 & 77.2 & 77.2 \\
1 juta sampai dengan 2 Juta & 7 & 7.0 & 12.3 & 89.5 \\
\hline
\end{tabular}


Siswanto

\begin{tabular}{|c|c|c|c|c|}
\hline Lebih dari dua Juta sampai 4 Juta & 2 & 20 & 3.5 & 93.0 \\
\hline Lebih dari 4 Juta & 4 & 4.0 & 7.0 & 100.0 \\
\hline Total & 57 & 57.0 & 100,0 & \\
\hline Missing System & 43 & 43.0 & & \\
\hline Total & 100 & 100.0 & & \\
\hline
\end{tabular}

Sumber: data diolah

Hasil analisis deskriptif menunjukkan bahwa sejumlah $4 \%$ (4 orang) responden yang telah memiliki penghasilan diatas 4 juta. Sedangkan sebagian besar responden yang telah memiliki usaha perpenghasilan kurang dari satu juta, yakni sejumlah $44 \%$.

Karakteristik responden berdasarkan penghasilan orang menjelaskan tentang jumlah pendapatan orang tua dari responden. Tabel 7. Data responden berdasarkan penghasilan orang tua

\begin{tabular}{lcccc}
\hline \multicolumn{1}{c}{ Penghasilan Orang Tua } & Frequency & Percent & $\begin{array}{c}\text { Valid } \\
\text { Percent }\end{array}$ & $\begin{array}{c}\text { Cumulative } \\
\text { Percent }\end{array}$ \\
\cline { 2 - 5 } Kurang dari Satu Juta & 19 & 19.0 & 19.0 & 19.0 \\
1 juta sampai dengan 2 Juta & 45 & 45.0 & 45.0 & 64.0 \\
Lebih dari dua Juta sampai 4 & 26 & 26.0 & 26.0 & 90.0 \\
Juta & 10 & 10.0 & 10.0 & 100.0 \\
Lebih dari 4 Juta & 100 & 100.0 & 100.0 & \\
Total & & &
\end{tabular}

Sumber: data diolah

Berdasarkan hasil analisis menunjukkan bahwa sebagian besar orang tua responden memiliki penghasilan antara satu juta sampai dengan dua juta rupiah, yakni sebanyak 45 orang atau $45 \%$. Disusul dengan pendapat antara lebih dari dua juta hingga empat juta rupiah, pendapatan orang tua kurang dari satu juta, dan lebih dari empat juga, masing-masing sebesar $26 \% ; 19 \%$, dan $10 \%$.

Karakteristik responden berdasarkan pekerjaan orang tua menjelaskan tentang data responden berdasarkan pekerjaan orang tua.

Tabel 8. Data responden berdasarkan pekerjaan orang tua

\begin{tabular}{lcccc}
\hline & Frequency & Percent & $\begin{array}{c}\text { Valid } \\
\text { Percent }\end{array}$ & Cumulative Percent \\
\cline { 2 - 5 } Wirausaha/Pedagang & 40 & 40.0 & 40.0 & 40.0 \\
PNS & 13 & 13.0 & 13.0 & 53.0 \\
Pegawai Swasta & 15 & 15.0 & 15.0 & 68.0 \\
\hline
\end{tabular}




\begin{tabular}{lcccc}
\hline Lainnya & 32 & 32.0 & 32.0 & 100.0 \\
Total & 100 & 100.0 & 100.0 & \\
\hline
\end{tabular}

Sumber: data diolah

Hasil analisis penelitian menunjukkan bahwa sebagian besar orang tua responden berprofesi sebagai wirausaha atau pedagang, yakni sejumlah 40 orang $(40 \%)$. Selanjutnya, orang tua responden berprofesi sebagai pegawai swasta, pegawai negeri (PNS) masingmasing sebesar $15 \%$ dan $13 \%$. Sedangkan sisanya memiliki profesi lain seperti petani atau nelayan atau kyai sejumlah $32 \%$.

Karakteristik responden berdasarkan sumber bacaan menjelaskan tentang kecenderungan responden untuk memilih bacaan yang sering dijadikan referensi.

Tabel 9. Data responden berdasarkan sumber bacaan

\begin{tabular}{lcccc}
\hline \multirow{2}{*}{$\begin{array}{c}\text { Sumber bacaan } \\
\text { Harian Umum }\end{array}$} & Frequency & Percent & $\begin{array}{c}\text { Valid } \\
\text { percent }\end{array}$ & $\begin{array}{c}\text { Cumulative } \\
\text { percent }\end{array}$ \\
\cline { 2 - 5 } & 35 & 35.0 & 35.0 & 35.0 \\
Surat kabar ekonomi dan bisnis & 17 & 17.0 & 17.0 & 52.0 \\
Surat kabar/majalah Entrepreneur & 29 & 29.0 & 29.0 & 81.0 \\
Lainnya & 19 & 19.0 & 19.0 & 100.0 \\
Total & 100 & 100.0 & 100.0 & \\
\hline
\end{tabular}

Sumber: data diolah

Berdasarkan hasil analisis deskriptif menunjukkan bahwa sebagian besar responden menyukai sumber bacaan harian umum dan selisih sedikit dengan bacaan yang berkaitan dengan masalah kewirausahaan. Responden yang memilih bacaan harian umum sebesar $35 \%$, sedangkan responden yang memilih bacaan majalah/media tentang kewirausahaan sebesar $29 \%$.

Karakteristik responden berdasarkan jenis kelamin dan niat berwirausaha menjalaskan tentang kesalingterhubungan responden berdasarkan jenis kelamin dan niat berwirausaha.

Tabel 10. Data responden berdasarkan jenis kelamin dan niat berwirausaha

\begin{tabular}{|c|c|c|c|c|c|}
\hline \multirow{4}{*}{$\begin{array}{l}\text { Jenis } \\
\text { Kelamin }\end{array}$} & & & \multicolumn{2}{|c|}{ Niat Berwirausaha } & \multirow[b]{2}{*}{ Total } \\
\hline & & & Memiliki Niat & $\begin{array}{c}\text { Tidak Memiliki } \\
\text { Niat }\end{array}$ & \\
\hline & Laki_Laki & Count & 38 & 1 & 39 \\
\hline & & $\%$ of Total & $38.0 \%$ & $1.0 \%$ & $39.0 \%$ \\
\hline
\end{tabular}




\begin{tabular}{|c|c|c|c|c|}
\hline & Perempuan Count & 60 & 1 & 61 \\
\hline \multirow{3}{*}{ Total } & s of Total & $60.0 \%$ & $1.0 \%$ & $61,0 \%$ \\
\hline & Count & 98 & 2 & 100 \\
\hline & $\%$ of Total & $98.0 \%$ & $2.0 \%$ & $100.0 \%$ \\
\hline
\end{tabular}

Sumber: data diolah

Berdasarkan hasil analisis tabulasi silang menunjukkan bahwa 2 responden yang tidak memiliki minat dalam memulai wirausaha adalah terdiri dari 1 orang laki-laki, dan satu orang perempuan. Sehingga sebagian besar responden perempuan memiliki niat memulai usaha, yakni sebesar $60 \%$.

\section{Uji Validitas dan Reliabilitas Instrumen}

Uji validitas merupakan uji homogenitas item pertanyaan per variabel. Sebenarnya validitas (validity, kesahihan) berkaitan dengan permasalahan "Apakah instrumen yang dimaksudkan untuk mengukur sesuatu itu memang dapat mengukur secara tepat sesuatu yang akan diukur tersebut". Secara singkat dapat dikatakan bahwa validitas alat penelitian mempersoalkan apakah alat itu dapat mengukur apa yang akan diukur. $\mathrm{Uji}_{\mathrm{i}}$ signifikansi dihitung dengan membandingkan nilai probabilitas masing-masing korelasi pada taraf signifikansi $5 \%$. Apabila probabilitas korelasi kurang dari dari $5 \%$, maka valid. Sebaliknya, jika nilai probabilitas korelasi lebih dari $5 \%$, maka item pertanyaan tersebut tidak valid. Dalam penelitian ini, jika ditemukan instrumen pertanyaan yang tidak valid maka item tersebut dibuang.

Instrument penelitian yang digunakan untuk menentukan determinan motivasi wirausaha mahasiswa muslim ini terdiri atas 26 item. Masing-masing item dipastikan validitasnya sebelum direduksi dalam faktor penentu (determinan) motivasi wirausaha. Berikut hasil uji validitas masing-masing item pertanyaan. Berdasarkan hasil analisis uji validitas dengan menggunakan metode pearson correlation menunjukkan bahwa seluruh nilai signifikansi kurang dari $1 \%$. Hal ini memiliki makna bahwa seluruh instrumen yang digunakan dalam penelitian adalah valid (shahih). Artinya, instrumen tersebut dapat digunakan untuk mengukur sesuatu secara tepat dan berguna dalam mengukur sesuatu yang akan diukur. Oleh karena itu, instrumen ini dapat dimanfaatkan dalam analisis lebih lanjut (Hasil analisis ada pada lampiran 1 tentang hasil analisis uji validitas). 
Uji reliabilitas merupakan kriteria tingkat kemantapan atau konsistensi suatu alat ukur (kuesioner). Suatu kuesioner dikatakan mantap bila dalam mengukur sesuatu secara berulang kali memberikan hasil yang sama dengan catatan bahwa kondisi saat pengukuran tidak berubah. Dalam uji reliabilitas, peneliti menggunakan metode konsistensi internal dengan teknik Cronbach's Alpha. Nilai Alpha antara 0,8 sampai 1,0 dikategorikan reliabilitas baik, nilai alpha antara 0,60 sampai 0,79 dikategorikan reliabilitas diterima, dan nilai kurang dari 0,60 dikategorikan reliabilitas kurang baik.

Tabel 11. Instrumen penelitian

\begin{tabular}{lcccc}
\hline & Mean & Minimum & Maximum & $\begin{array}{c}\text { Cronbach's } \\
\text { Alpha }\end{array}$ \\
\cline { 2 - 5 } Item Means & 4.128 & 3.680 & 4.640 & .783 \\
Inter-Item Correlations & 270 & -.108 & .680 & \\
\hline
\end{tabular}

Sumber data diolah

Hasil analisis reliabilitas instrumen motivasi wirausaha mahasiswa muslim menunjukkan bahwa nilai Cronbach's Alpha dari 26 item pertanyaan menunjukkan nilai sebesar 0,783 . Instrumen yang memiliki tingkat reliabilitas diterima jika nilai Cronbach's Alpha berkisar antara $0,60 \mathrm{~s} / \mathrm{d} 0,79$. Oleh karena itu, instrumen seluruh instrumen yang digunakan dalam penelitian ini telah memenuhi standar instrumen reliabel. Nilai rata-rata item seluruh instrument sebesar 4,128 . Sedangkan nilai minimum dan nilai maksimum masing-masing sebesar 3,680 dan 4,640. Berdasarkan hasil analisis menunjukkan bahwa instrumen dalam penelitian ini reliabel. Artinya, setiap instrumen yang digunakan memiliki konsistensi dan kemantapan dalam alat ukumya.

\section{Hasil Uji Analisis Faktor dan Pembahasan}

Analisa faktor merupakan salah satu teknik analisa yang interdipenden dimana semua variabel secara simultan dipertimbangkan, semua variabel saling terkait satu dengan yang lainnya. Hasil analisis faktor-faktor yang menentukan motivasi wirausaha (entrepreneurial motioation) mahasiswa muslim jurusan perbankan syariah menunjukkan ada 6 faktor yang terbentuk. Instrumen tersebut mengelompok pada nilai komunalitas yang memiliki keeratan hubungan. Hasil output tersebut dapat dikelompokkan sebagai berikut; 
NO. FAKTOR

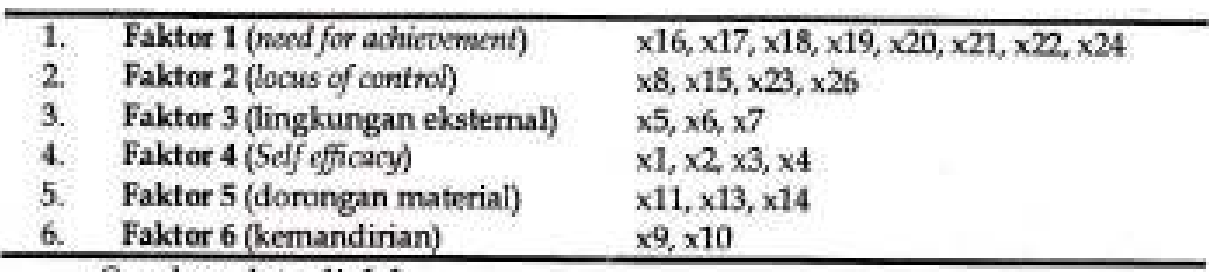

Sumber: data diolah

Proses analisis faktor secara garis besar menurut Hair et al., (1998: 87) meliputi beberapa tahapan berikut, 1) Memilih variabel yang layak dimasukkan dalam analisis faktor, 2) Setelah sejumlah variabel terpilih, maka dilakukan ekstraksi variabel tersebut hingga menjadi satu atau beberapa faktor, 3) Faktor yang terbentuk, pada banyak kasus, kurang menggambarkan perbedaan diantara faktor-faktor yang ada, maka diperlukan proses rotasi untuk memperjelas apakah faktor yang terbentuk sudah secara signifikan berbeda dengan faktor lain, dan 4) Menamakan faktor yang ada.

Berdasarkan hasil analisis terbentuk 6 faktor yang terbentuk. Beberapa tahap yang digunakan telah disesuaikan dengan proses dalam analisis faktor. Proses rotasi merupakan faktor akhir yang ditunjukkan dalam tabel 4,18. Hasil analisis faktor menemukan 6 faktor yang diberikan identitas sebagai faktor kebutuhan berprestasi (need for achievement), kendali internal (locus of control), lingkungan eksternal, dorongan internal (self-efficacy), dorongan material, dan kemandirian.

Motivasi merupakan alasan yang mendasari sebuah perbuatan yang dilakukan oleh seorang individu. Alasan yang mendasari perbuatan dalam Islam disebut dengan niat. Menurut theory of planned belavior yang dikembangkan oleh Ajzen (1991), niat (intention) diasumsikan sebagai faktor-faktor motivasional yang mempengaruhi perilaku. Niat ini menunjukkan seberapa kuat orang berupaya untuk mencoba, seberapa besar upaya yang direncanakan untuk mencapainya dalam rangka untuk melakukan perilaku. Sebagai bentuk dari kesimpulan umum bahwa semakin kuat dan semakin besar niat untuk terlibat dan melakukan suatu perilaku tertentu, maka kinerja yang akan dicapai semakin tinggi.

Ajzen (1991: 180) menyatakan bahwa; "The idea that behtavioral achievement depends jointly on motivation (intention) and ability (behavioral control) is by no means new, Lebih lanjut, Ajzen (1991) berpendapat 
bahwa niat dipengaruhi oleh sikap (attitude), kendali perilaku yang diharapkan (perceized behavior control), serta norma atau nilai-nilai subyektif.

Konsep need for achiecement (kebutuhan berprestasi) banyak mendapat perhatian dalam wilayah riset karakter kepribadian dan entrepreneurship (Shane, at al., 2003). Pillis \& Reardon (2007) menunjukkan peran faktor sifat-sifat kepribadian achievement motivation menentukan keberhasilan aktivitas entrepneneurship. Orang yang memiliki tingkat kebutuhan berprestasi tinggi senang bersaing dengan standar keunggulan dan memilih untuk bertanggung jawab secara pribadi atas tugas dibebankan padanya memiliki peran penting dalam keberhasilan proses entrepreneurship (Longenecker, et al., 2000. 10). Ahmad (2010) menunjukkan tingkat motivasi need for achiezement para CEO perusahaan di Pakistan menentukan keberhasilan dalam organisasinya. Para CEO perusahaan di Pakistan yang memiliki motivasi need for achiezement tinggi lebih berhasil, dibandingkan dengan CEO professional biasa. Pandey (2011) menunjukkan keberhasilan proses entrepreneurship di Uttar Pradesh India ditentukan oleh karakteristik need for achievement.

Salah satu sifat yang menentukan motivasi entrepreneurship adalah locus of control (Shane, et al., 2003). Locus of control berkaitan dengan tingkat sejauh mana seorang individu menyakini tindakan mereka atau karakteristik personalnya menentukan hasil (Robbins, 2006: 132; Shane, et al., 2003). Robbins (2006: 132) menyatakan bahwa seorang individu yang memiliki internal locus of control menyakini bahwa mereka mengendalikan apa yang terjadi pada mereka. Sedangkan, orang yang memiliki external locus of control menyakini bahwa apa yang terjadi pada mereka dikendalikan oleh kekuatankekuatan luar seperti nasib dan kesempatan. Pillis \& Reardon (2007) menunjukkan peran faktor sifat-sifat kepribadian locus of control menentukan keberhasilan aktivitas entrepreneurship. Pandey (2011) menunjukkan variabel locus of control menentukan keberhasilan proses entrepreneurship di Uttar Prades India. Littunen (2000) menunjukkan bahwa terdapat perbedaan locus of control para pengusaha yang bergerak pada industri logam di Finlandia. Berdasarkan hasil analisis, para pengusaha di Finlandia semakin tinggi internal locus of control seiring dengan berjalannya waktu dan pengalaman yang didapatkannya.

Selama beberapa tahun, penelitian tentang entrepreneurship seringkali dihubungkan dengan peran faktor lingkungan eksternal (Fereidouni et al., 2010). Walaupun penelitian-penelitian tersebut 
memberikan pemahaman yang semakin jelas terhadap proses entrepreneurship, namun penelitian tersebut mengabaikan peran manusia. Entrepreneurship akan tergantung pada pengambilan keputusan yang dilakukan orang tentang bagaimana untuk menjalankan proses tersebut. Penelitian ini memiliki pendapat yang sama dengan pernyataan Shane et al. (2003) bahwa peran manusia ketika memutuskan melakukan proses entrepreneurial akan mempengaruhi keberhasilan proses tersebut.

Kemandirian (Independence) mencakup mengambil tanggung jawab untuk menggunakan pertimbangan sendiri sebagai lawan dari secara membabi buta mengikuti penegasan orang lain. $\mathrm{Hal}$ ini juga melibatkan mengambil tanggung jawab atas kehidupan sendiri, bukan hidup dari usaha orang lain (Shane, et al., 2003). Sarri and Trihopoulou (2005) menunjukkan motivasi para entrepreneur pria di Yunani adalah faktor autonony \& independence, self-fulfillment, serta need for creativity. Kirkwood and Walton (2009) melakukan explorasi motivasi ecopreneurship. Menurut Kirkwood and Walton (2009) ecopreneurs merupakan para entrepreneur dimana dalam memulai bisnis dengan mendasari pada green tulues dan memasarkan green products or services. Hasil penelitian menurjukkan bahwa para ecopreneur termovitasi salah satu keinginan untuk mandiri dan menjadi oun boss.

Selfefficacy merupakan salah satu karakteristik individu yang penting yang menentukan keinginan dan perilaku entrepreneurial (Pihie \& Bagheri, 2011: Drnnovsek, Wincent, Cardon, 2009; Shane, et al., 2003). Longenecker, ef al., (2000: 10) menjelaskan bahwa selfefficacy merupakan keyakinan yang dimiliki oleh seseorang bahwa dirinya mampu untuk menghadapi tantangan yang ada di depan mereka. Pihie \& Bagheri (2011) menunjukkan seseorang yang memiliki tingkat selfefficacy tinggi memiliki kecenderungan untuk menjadi pengusaha di tiga negara, yakni Rusia, Norwegia dan Finlandia.

\section{DAFTAR PUSTAKA}

Ahmad, H.M. 2010. Personality Traits among Entrepreneurial and Professional CEO SMEs, Intemational Journal of Business and Management, Vol. 5 No. 9

Ajzen, I. 1991. The Theory of Planned Behavior, Organizational Behavior and Human Decision Process, 50, 179-211 
Benzing, C. and Chu, H.M. 2009. A Comparation of Motivation of Small Business Owner in Africa, Jotrnal of Small Business and Entreprise Development, Vol. 16 No. 1. Pp. 60-77.

Carsrud, A., Brannback, M. 2011. Entrepreneurial Motivations: What Do We Still Need to Know? Journal of Small Business Management, 49 (1), pp. $9-26$

Djakfar, M. 2010. Teologi Ekonomi: Membumikan Titah Langit di Ranah Bisnis. Malang; UIN-Malang Press

Drnnovsek, M., Wincent, J., Cardon, M.S., 2009. Entrepreneurial SelfEfficacy and Business Start-Up: Developing a MultiDimensional Definition, International Journal of Entrepreneurial Behaviour \& Research Vol. 16 No. 4, pp. 329 348

Edelman, L.F., Brush, C.G., Manolova, C.S., Greene, P.G. 2010. StartUp Motivation and Growth Intention of Minority Nascent Entrepreneurs, Journal of Small Business Management, Vol. 48 No. 2 pp. 174-196

Fereidouni, H.G., Masron, T.A., Nikbin, D., Amiri, R.E. 2010. Consequences of External Environment on Entrepreneurial Motivation in Iran, Asian Acedemy of Manngement Journal, Vol. 15 No. 2 pp. $175-196$

Gnyawali, D. R., \& Fogel, D. S. 1994. Environments for Entrepreneurship Development Key Dimensions and Research Implications. Entrepreneurship Theory and Practice, 18(4), 43-62.

Gorman G., Hanlon D., King W. 1997. Some Reseacrh Perspective on Entrepreneurship Education for Small Business Management: a ten-year literature review. International Small Business Journal. April-June v15 $n 3$ p56(22)

Hair J.F., Anderson, R.E, Tatham, R.L., Black, W.C. 1998. Multivariate Data Analysis. London: Prentice Hall

Hamid, S.A. and Sa'ari, C.Z. 2011. Reconstructing Entrepreneur's Development Based on al-Qur'an And al-Hadith. International Journal of Business and Social Science Vol. 2 No. 19

Harefa, A. Siadari, E. E. 2008. Tiue Ciputra's Winy Praktik Terbaik Menjadi Entrepreneur Sejati, Elex Media Komputindo, Jakarta.

Hidayat, K 2002. Human Growth and Responsibility. Jurnal Universitas Paramadina, Vol. 2 No. 1

Huarng, K.H. and Yu, T.H.K 2011. Entrepreneurship, Process Innovation and Value Creation by a Non-Profit SME, Management Decision, Vol. 49 No. 2 
Huarng, K.H. and Yu, T.H.K. 2011. Entrepreneurship, Process Innovation and Value Creation by a Non-Profit SME, Management Decision, Vol. 49 No. 2

Ismail, A.M., Othman, M.Y., and Dakir, J. 2011. The Development of Human Behavior: Islamic Approach, Jumal Hadhari, 3 (2) 103 116

Ismail, M. 1999. Bunga Rampai Pemikiran Islam, (Penerjemah: Nurkhalis). Jakarta: Gema lnsani Press

Jakee, K and Spong, H. 2003. Praxeology, Entrepreneurship and the Market Process: A Review of Kizner's Contribution, journal of the History of Economic Thought, Vol. 25 No. 4, pp. 461-86

Kanto, S. 2003. Sampling, Validitas dan Reliabilitas dalam Penelitian Kualitatif, PT. RajaGrafindo, Jakarta.

Kao, J. 1989. Entrepreneurship, Creativity and Organizntion: Text, Cases and Readings. Prentice Hall, New Jersey.

Karim, Adiwarman A. 2004. Sejamh Pemikiran Ekononü Islam. Jakarta: Rajawali Press

Kasali, R. 2010. Wirausaha Muda Mandiri: Ketika Anak Sekolahan Berbisnis. Jakarta: PT. Gramedia Pustaka Utama

Kasali, R. 2010, Myelin: Mobilisasi Intangibles Menjadi Kekuatan Perubuhan. Jakarta: PT. Gramedia Pustaka Utama

Kasali, R. 2011. Wirausaha Muda Mandiri: Ketika Anak Sekolalıan Berbisnis Part 2. Jakarta: PT. Gramedia Pustaka Utama

Katsikis I.N., Kyrgidou L.P. 2009. Entrepreneurship in Teleology: The Variety of the Forms, International Journal of Entrepreneurial Behuoior \& Research, Vol. 12 No.2, pp. 209-231

Kauanui, S.K., Thomas, K.D., Sherman, C.L., Waters, G.R., Gilea, M. 2010. An Exploration of Entrepreneurship and Play, Joumal of Organizational Change Management, Vol. 23 No. 1, pp. 51-70

Kauanui, S.K., Thomas, K.D., Sherman, C.L., Waters, G.R, Gilea, M. 2010. An Exploration of Entrepreneurship and Play, Journal of Organizational Change Management, Vol. 23 No. 1, pp. 51-70

Kawi, A., and Kole, J. 1991. An Islamic Perspective on ExpectancyValence Theory, The American Journal of Islamic Social Science, Vol. 8 No. 3

Kawi, A., and Kole, J. 1991. An Islamic Perspective on ExpectancyValence Theory, The American Joumal of Islamic Social Science, Vol. 8 No. 3

Kelana, M. 2008. Muhammad SAW is the Great Entrepreneur. Bandung: Dinar Publishing 
Kirkwood, J. 2009. Motivational Factors in Push-Pull Theory of Entrepreneruship, Gender in Management: An International joumal. Vol. 24 No. 5

Kirkwood, J., Walton, S. 2010. What Motivates Ecopreneurs to Start Business. International Journal of Entrepreneurship Behavior and Research. Vol. 16 No. 3

Klyver, K., and Hindle, K 2007. The Role Of Social Networks At Different Stages of Business Formation. Small Business Research.Vol. 15 No. 1

Kuswarno, E. 2009. Metode Penelitian Komunikasi Fenonenolog: Konsepsi, Pedoman, dan Contoh Penelitian. Widya Padjadjaran

Lewin, P. 1999. Capital in Disequilibrium, Routledge, New York, NY.

Lincoln, Y.S. and Guba, E.G. 1985. Naturalistic Inquiny. Baverly Hills, CA: Sage Publication

Lindlof, T.R. 1995. Qualitative Commenication Research Method. London: Sage Publication

Littunen, H. 2000. Entrepreneurship and the Characteristics of the Entrepreneurship Personality. International Journal of Entrepreneurship Behmior and Research. Vol. 6 No. 6

Littunen, H. 2000. Entrepreneurship and the Characteristics of the Entrepreneurship Personality. International Journal of Entrepreneurship Behavior and Research. Vol. 6 No. 6

Longenecker J.G., Moore C.W., Petty J.W. 2000. Small Business Management: An Entrepreneurial Emphasis 11 ${ }^{\text {th }}$ Ed. Devision of Thomson Learning Asia (Penerjemah) Kewirausahaan Manajemen Usaha Kecil, Salemba Empat,Jakarta.

Longenecker J.G., Moore C.W., Petty J.W. 2000. Small Business Management: An Entrepreneurial Emphasis 11 1 fi Ed. Devision of Thomson Learning Asia (Penerjemah) Kewirausahaan Manajemen Usaha Kecil, Salemba Empat,Jakarta.

Luthans, F. 2002. Organizational Behnvior. New York: McGraw-Hill McShane, S.L., and Von Glinow, M.A. Organizational Behavior 2sd Ed. Boston: McGraw-Hill Irwin

Pandey, V. 2011. An Analytical of Entrepreneurial Success Factors in Uttar Padesh. Asian joumal of Technology and Management Resencrin, Vol.01 No, 01

Pihie, Z.A.L., and Bagheri, A. 2011. Are Teacher Qualified to Teach Entrepreneurship? Analysis of Entrepreneurial Attitude and Self Efficacy, Journal of Applied Science, Vol. 11 No. 18, pp. 3308-3314 
Pillis E.,D. and Reardon, K.K. 2007. The Influence of Personality Traits and Persuasive Message on Entrepreneurial Intention, Career Development Intemational, Vol. $12 \mathrm{No}, 4$, pp. 382-396

Robbins, S.P. 2006. Organizational Behurvior, 10 $\mathrm{kd}$. Prentice Hall. (pent. Benyamin Molan) Perilaku Organisasi, Jakarta: PT. Indeks

Sarri, K. and Trihopoulou, A. 2005. Female Entrepreneurs' Personal Characteristics and Motivation: A Review of the Greek Situation, Journal Women in Management Recierv, Vol. 20 No, 1 pp. $24-36$

Shane, S. and Venkataraman, S. 2000. The Promise of Entrepreneurship as a Field of Research, Academy of Manngement Review, Vol. 25 No. 1, pp. 217-26

Shane, S., Locke, E.A., Collins, C.J. 2003. Entrepreneurial Motivation, Human Resource Management Review, 13 (2003) 257-279

Shook, C.L., Priem, R.L., McGee, J.E. 2003. Venture Creation and the Enterprising Individual: A Review and Synthesis, Journal of Manngement, 29; 379

Siswanto., Armanu., Setiawan, M., \& Nimran, U. (2013). Entrepreneurial Motivation in Pondok Pesantren. Intemational Journal of Business and Behuioional Sciences Vol. 3 No, 2, $42-54$.

Stewart, W,H., Carland, J.C., Carland, J.W. 2004. Is Risk Taking Propensity an Attribute of Entrepreneurship? A Comparative Analysis of Instrumentation, http://www.sbaer.uca.edu/research/1998/ASBE/98asb051.tx t

Umar, H. 2003. Metode Riset Perilaku Organisasi. Jakarta. PT. Gramedia Pustaka.

Valliere, D. 2008. Exploring Buddhist Influence on the Entrepreneurship Decision. International Journal of Entrepreneurship Behavior and Research. Vol. 14 No. 3

Yazilmiwati and IThaamie, 2011. The Motivation of Islamic Studies' Student to be Entrepreneurs: A Study of Undergraduate and Postgraduate Students in A Public University. 2nd International Conference on Business and Econonic Research (2nd Iober 2011) Proceeding 
Lampiran 1. Tabel Hasil analisis uji validitas

\begin{tabular}{|c|c|c|}
\hline & & Output \\
\hline \multirow[t]{3}{*}{$\mathrm{x} \mathbf{1}$} & Pearson Correlation & $442^{-}$ \\
\hline & $5 \operatorname{sg}(2-$ tsiled $)$ & .000 \\
\hline & $\mathrm{N}$ & 100 \\
\hline \multirow[t]{3}{*}{$x 2$} & Pearson Correlation & $471^{-}$ \\
\hline & Sig, (2-tailed) & .000 \\
\hline & $\mathrm{N}$ & 100 \\
\hline \multirow[t]{3}{*}{$x^{3}$} & Pearson Correlation & $555^{\prime \prime}$ \\
\hline & Sig (2-tailed) & .000 \\
\hline & $\mathrm{N}$ & 100 \\
\hline \multirow[t]{3}{*}{$x 4$} & Pearson Correlation & $611^{\prime \prime}$ \\
\hline & Sig. (2-tailed $)$ & .000 \\
\hline & $\mathrm{N}$ & 100 \\
\hline \multirow[t]{2}{*}{35} & Pearson Correlation & $.530^{\circ}$ \\
\hline & Sig (2-tailed) & .000 \\
\hline 3 & $\mathrm{~N}$ & 100 \\
\hline \multirow[t]{2}{*}{$x 6$} & Pearson Correlation & $560^{\circ}$ \\
\hline & Sig (z-tasled) & .000 \\
\hline \multirow{5}{*}{ 35: } & N & 100 \\
\hline & Pearson Correlation & $458^{\circ}$ \\
\hline & Sig (2-tailed) & .000 \\
\hline & $\mathrm{N}$ & 100 \\
\hline & Pexrson Correlation & $.614^{-}$ \\
\hline & Sig, (2-ailed) & .000 \\
\hline$(F-5)$ & $\mathrm{N}$ & 100 \\
\hline \multirow[t]{3}{*}{$x 9$} & Pearson Corrolation & $641^{*}$ \\
\hline & Sig (2-tailed) & .000 \\
\hline & $\mathrm{N}$ & 100 \\
\hline \multirow[t]{3}{*}{$x 10$} & Pedrson Comelation & $456^{\circ}$ \\
\hline & Sig, (2-tailed) & .000 \\
\hline & $\mathrm{N}$ & 100 \\
\hline \multirow[t]{3}{*}{$\times 11$} & Pearson Correlation & $442^{\circ}$ \\
\hline & Sigp (2-tailed) & .000 \\
\hline & $\mathrm{N}$ & 100 \\
\hline \multirow[t]{3}{*}{$\times 12$} & Pearson Carrelation & $521^{\prime \prime}$ \\
\hline & Sig (2-tailed) & .000 \\
\hline & $\mathrm{N}$ & 100 \\
\hline \multirow[t]{3}{*}{$x 13$} & Peersen Coerelabion & $373^{-}$ \\
\hline & Sig (2-thiled) & 000 \\
\hline & $\mathrm{N}$ & 100 \\
\hline \multirow[t]{2}{*}{$\mathrm{x} 14$} & Pearson Correlation & $A 58^{\prime \prime}$ \\
\hline & Sig, (2-tailed) & .000 \\
\hline
\end{tabular}




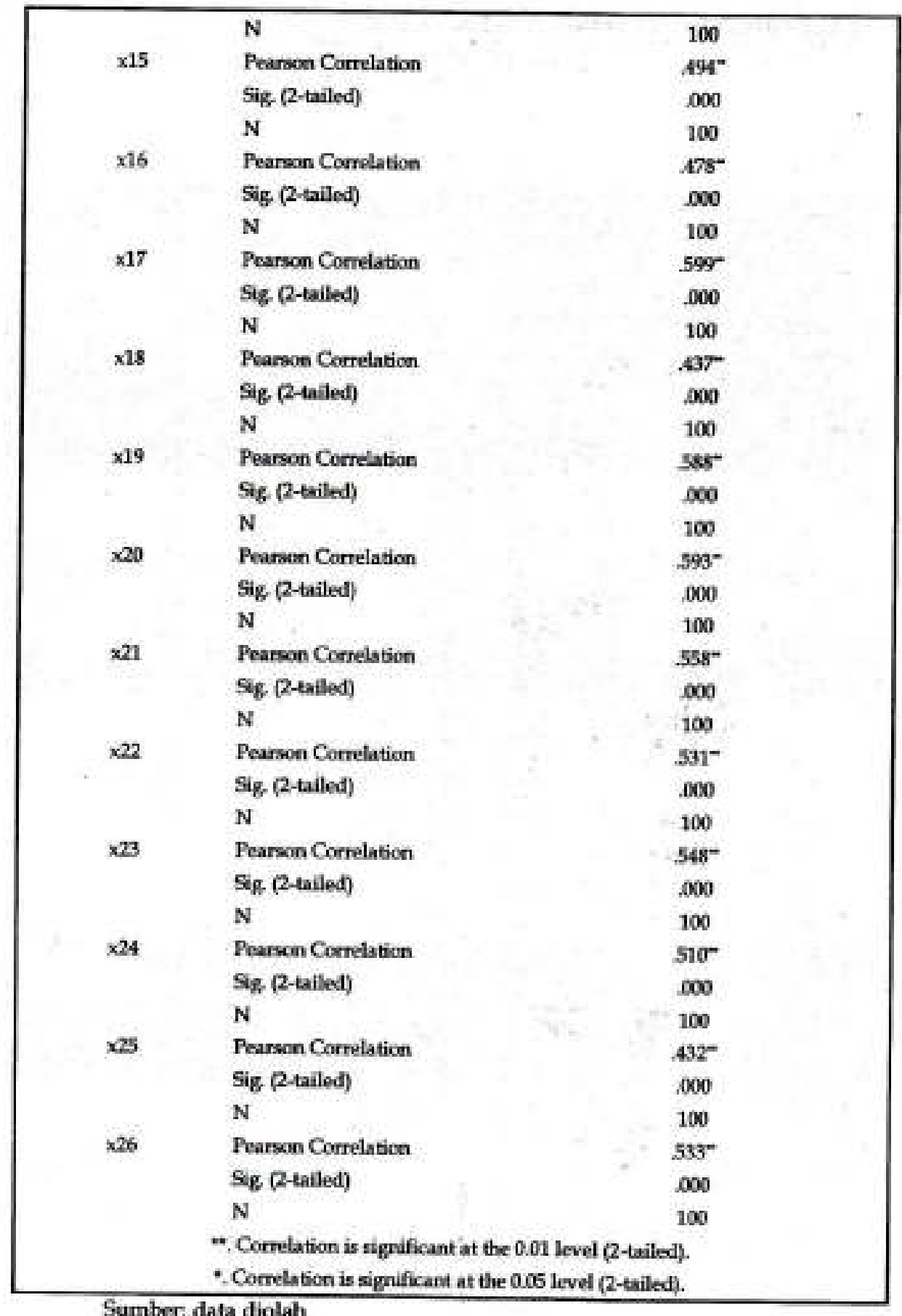

Sumber data diolah 
Determinan Enterpreneurial Motivation

\section{Lampiran 2 Tabel Hasil Analis Faktor}

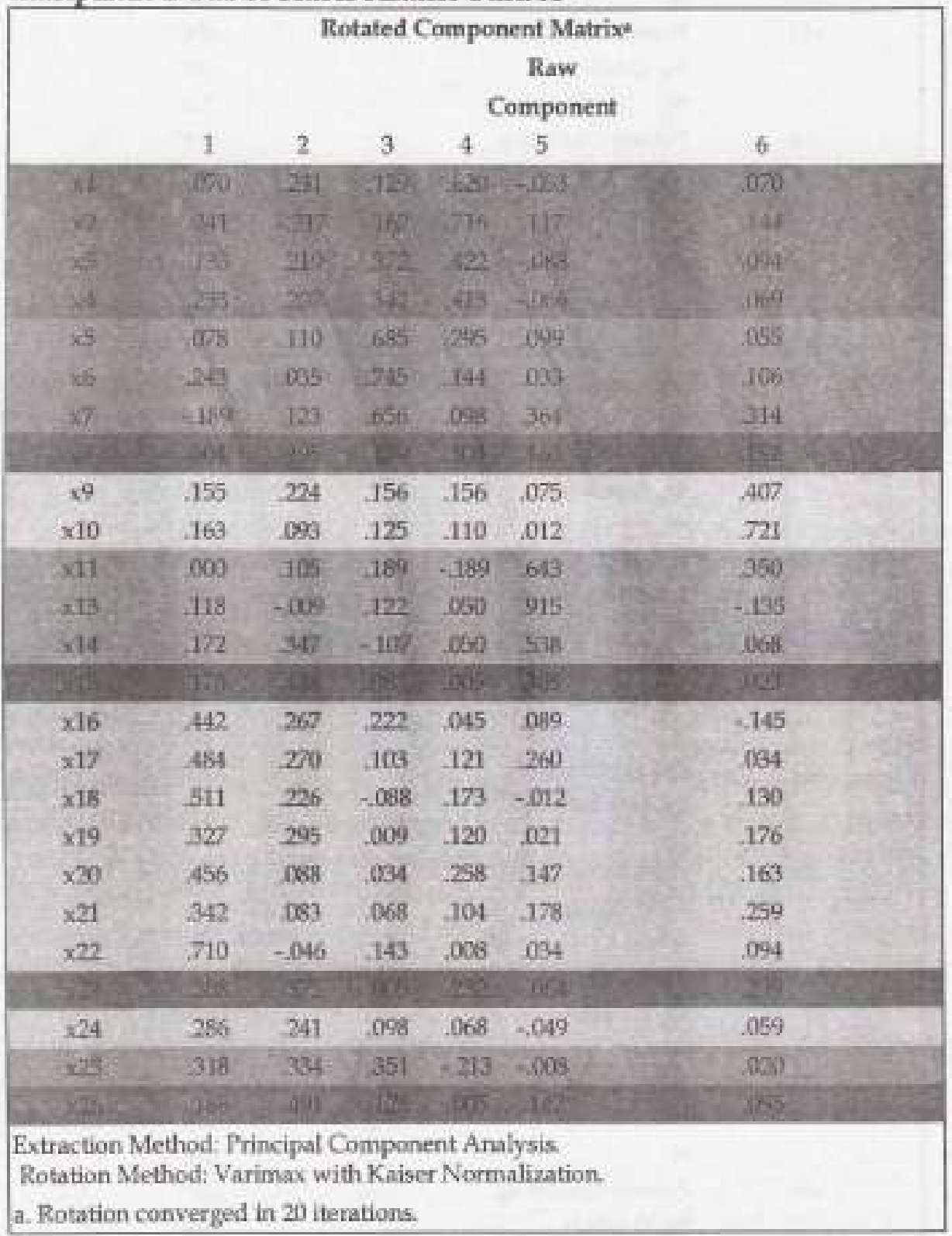

